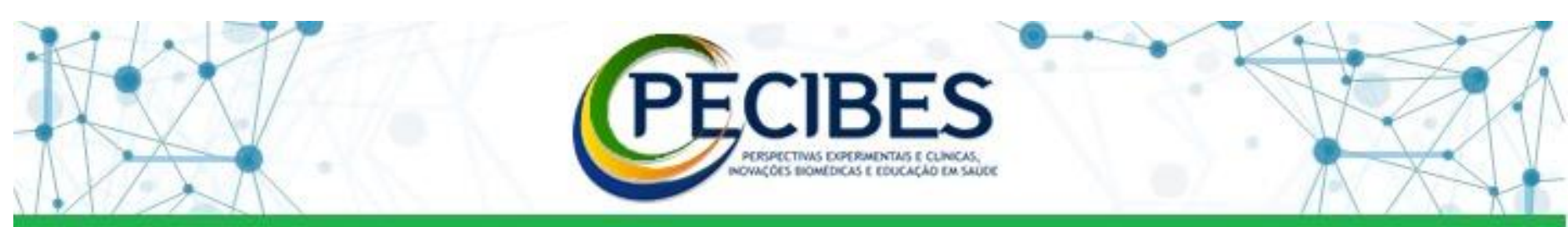

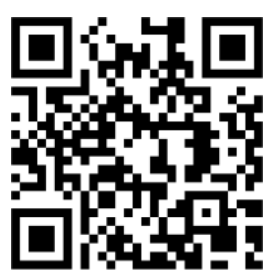

http://www.seer.ufms.br/i ndex.php/pecibes/index

* Autor correspondente: Lúcio Barbosa Neto, Universidade Federal de

Mato Grosso do Sul UFMS. E-mail do autor:

lucioobarbosa84@g mail.com

Descritores:

Burnout;

Qualidade de vida;

Capacidade de trabalho;

Professores.

Key-words: Burnout; Quality of life; Ability to work; Teachers.

\section{Avaliação da qualidade de vida, índice de capacidade para o trabalho e prevalência da síndrome de burnout em professores da rede municipal de ensino de Campo Grande, MS.}

Evaluation of quality of life, work capacity index and prevalence of burnout syndrome in teachers of the municipal education network of Campo Grande, MS.

\section{Lúcio Barbosa Neto ${ }^{1}$, Thomaz Nogueira Burke ${ }^{2}$, Liliane Pinho de Almeida, Priscilla Santana Bueno ${ }^{3}$}

1. Especialista em Metodologia da Educação Física; Mestrando em Ciências do Movimento, Universidade Federal de Mato Grosso do Sul.

2. Fisioterapeuta. Doutor. Professor Adjunto na UFMS/INISA

3. Doutor em Fisiopatologia Experimental pela Universidade de São Paulo. Campo Grande, Mato Grosso do Sul/Brasil.

Introdução: Dados do INEP, (MEC/2020), neste Estado são, 21.192 professores atuam no ensino fundamental, sendo que 13.619 atuam nos anos iniciais e 11.094 atuam nos anos finais. Em Campo Grande, são 408 professores atuantes no nível fundamental na rede municipal de ensino. A esfera de atuação escolar engloba diversas formas de representação, como atividades de coordenação, supervisão pedagógica e direção. Estas atividades têm sido apontadas como fatores estressantes e de repercussão negativa saúde dos trabalhadores da educação. Objetivo: Portanto, este trabalho tem por objetivo avaliar a qualidade de vida e a capacidade de trabalho e identificar a prevalência da síndrome de burnout em professores do ensino fundamental da rede Municipal de Ensino de Campo GrandelMS. Materiais/Métodos: Este estudo foi aprovado pelo Comitê de Ética em Pesquisa em Seres Humanos (CEP/UFMS; parecer 3.854.433, de 21/02/2020). O trabalho foi desenvolvido nas escolas públicas que oferecem o nível de Ensino Fundamental da administração municipal, localizadas na região urbana de Campo Grande, Mato Grosso do Sul. Resultados: A amostra foi composta por 202 professores atuantes na rede municipal de educação que lecionam no ensino fundamental I e II. Quando analisados os domínios de qualidade de vida, foram encontrados os seguintes valores. Domínio físico (60,5 $\pm 13,3)$; psicológico:(64,4 $\pm 15,8)$; $\operatorname{social}(64,6 \pm 17,0)$; ambiental $(53,2 \pm 12,2)$. A maioria dos professores avaliaram sua qualidade de vida como BOA $(49 \%)$. Com referência ao ICT, que avalia a capacidade física, mental e social dos trabalhadores, a média encontrada foi de 38,9 99,8 . Ele representa moderado ICT para 29,2\% e bom para $70,8 \%$ da amostra. A proporção de pessoas com bom ICT é significativamente maior que a proporção de pessoas com moderado ICT.No tocante ao índice de burnout notouse uma significativa proporção de participantes com cansaço emocional (37,1\%). A maioria dos participantes não apresenta sintoma de despersonalização $(75,7 \%)$ e apresenta alto índice de realização pessoal $(58,4 \%)$. Esta investigação indica a necessidade de ampliar estudos que aprofundem nos resultados encontrados e tragam mais respostas sobre a situação da saúde docente. 